\title{
Interventional bronchoscopy in malignant central airway obstruction by extra-pulmonary malignancy
}

\author{
Beomsu Shin ${ }^{1}$, Boksoon Chang ${ }^{2}$, Hojoong $\mathrm{Kim}^{3}$ and Byeong-Ho Jeong ${ }^{3^{*}}$ (D)
}

\begin{abstract}
Background: Interventional bronchoscopy is considered an effective treatment option for malignant central airway obstruction (MCAO). However, there are few reports of interventional bronchoscopy in patients with MCAOs due to extra-pulmonary malignancy. Therefore, the objective of this study was to investigate treatment outcomes and prognostic factors for bronchoscopic intervention in patients with MCAO due to extra-pulmonary malignancy.

Methods: We retrospectively analyzed consecutive 98 patients with MCAO due to extra-pulmonary malignancy who underwent interventional bronchoscopy between 2004 and 2014 at Samsung Medical Center (Seoul, Korea).

Results: The most common primary site of malignancy was esophageal cancer (37.9\%), followed by thyroid cancer (16.3\%) and head \& neck cancer (10.2\%). Bronchoscopic interventions were usually performed using a combination of mechanical debulking (84.7\%), stent insertion (70.4\%), and laser cauterization (37.8\%). Of 98 patients, 76 (77.6\%) patients had MCAO due to progression of malignancy, and 42 (42.9\%) patients had exhausted all other anti-cancer treatment at the time of bronchoscopic intervention. Technical success was achieved in $89.9 \%$ of patients, and acute complications and procedure-related deaths occurred in $20.4 \%$ and $3.1 \%$ of patients, respectively. Reduced survival was associated with MCAO due to cancer other than thyroid cancer or lymphoma, mixed lesions, and not receiving adjuvant treatment after bronchoscopic intervention.

Conclusions: Bronchoscopic intervention could be a safe and effective procedure for MCAO due to end-stage extra-pulmonary malignancies. In addition, we identified possible prognostic factors for poor survival after intervention, which could guide clinicians select candidates that will benefit from bronchoscopic intervention.
\end{abstract}

Keywords: Interventional bronchoscopy, Malignant central airway obstruction, Extra-pulmonary malignancy

\section{Background}

Malignant central airway obstruction (MCAO) is clinically significant and is usually considered as a criterion for intervention; it is usually defined as $\geq 50 \%$ occlusion of the cross-sectional area of the trachea, mainstem bronchi, bronchus intermedius, or lobar bronchus [1]. MCAO can cause dyspnea, hemoptysis, atelectasis, and obstructive pneumonia, and is associated with decreased quality of life and increased mortality [2, 3]. However, treatments to resolve MCAOs have many limitations. Surgery is restrictively performed according to the

\footnotetext{
* Correspondence: myacousticlung@gmail.com
${ }^{3}$ Division of Pulmonary and Critical Care Medicine, Department of Internal Medicine, Samsung Medical Center, Sungkyunkwan University School of Medicine, 81 Irwon-ro, Gangnam-gu, Seoul 06351, South Korea

Full list of author information is available at the end of the article
}

location of the lesion, stage of the disease, and the general medical condition of each patient [4]. In addition, long periods of chemotherapy and radiation therapy may be needed to resolve airway obstruction [5]. On the other hand, bronchoscopic intervention can immediately alleviate symptoms related to airway obstruction and improve quality of life $[1,6,7]$.

In total, $20-50 \%$ of patients with extra-pulmonary malignancy will have lung metastasis during their clinical course [8]. In addition, endobronchial metastases may occur in $1-4 \%$ of patients with extra-pulmonary malignancy $[9,10]$. Finally, extra-pulmonary malignancy comprises $8-40 \%$ of all MCAO cases [1, 11, 12]. However, most studies have conducted analyses without classification based on primary malignancy sites, such as 
pulmonary and extra-pulmonary malignancies $[1,6,11-$ $15]$. Based on these reports, there are limitations when managing patients with MCAO from an extrapulmonary malignancy.

Herein, we conducted a retrospective study to evaluate the clinical outcomes and prognostic factors of bronchoscopic interventions in patients with MCAO due to extra-pulmonary malignancy.

\section{Methods}

\section{Patients}

We retrospectively reviewed all interventional bronchoscopy reports from January 2004 to December 2014 at Samsung Medical Center (a 1979-bed, tertiary care referral hospital in Seoul, South Korea) and identified 98 patients with MCAO due to extra-pulmonary malignancy. This study obtained approval from the institutional review board (IRB no. 2017-01-033) to review and publish information obtained from patient records. The need for informed consent was waived because patient information was anonymized and de-identified prior to analysis.

\section{Airway intervention techniques}

Airway anatomy was evaluated using chest computed tomography $(\mathrm{CT})$ and, when possible, flexible bronchoscopy. MCAO was defined as $\geq 50 \%$ occlusion of the cross-sectional area of the trachea, main stem bronchi, bronchus intermedius, or lobar bronchus on the CT images or bronchoscopic findings [1].

Interventional bronchoscopy was performed according to standard techniques [16, 17]. After induction of general anesthesia, the patient was intubated with a rigid bronchoscope tube (Bryan Co., Woburn, MA, USA or Karl-Storz, Tuttlingen, Germany). Depending on the characteristics of airway obstruction (endobronchial lesion, extrinsic compression, and mixed lesion) and the medical condition of the patient, various combinations of airway intervention techniques were used, including mechanical debulking, laser, and insertion of silicone stents. Any endobronchial lesion was removed mechanically using rigid bronchoscope tubes and forceps. A neodymium-doped yttrium aluminum garnet laser (LaserSonics, Milpitas, CA, USA) or a diode laser (Biolitec, Ceralas, Germany) were used to cauterize visible vessels before mechanical debulking or to ablate residual endobronchial tumor. Additionally, if needed, a silicone stent (Natural stent [M1S Co., Seoul, Korea] or Dumon stent [Novatech, La Ciotat, France]) was inserted to maintain airway patency against extrinsic compression or rapid progression [18].

Technical success was based on anatomic criteria, which were defined as the reopening of the airway lumen to $>50 \%$ of the normal cross sectional area and a connection to a viable area of distal lung by bronchoscopy [1]. If a physician successfully reopened a proximal airway, but then discovered distal lesions that occluded all segmental or subsegmental levels, this was classified as a technical failure [1].

\section{Data collection}

We retrospectively reviewed the medical records of all 98 patients. The following data were collected: demographic characteristics, primary site of malignancy, bronchoscopic findings (site of lesion, type of obstruction, and severity and length of stenosis), pre- and postprocedure treatment modalities, techniques applied during bronchoscopic interventions, procedure-related complications, and survival time.

Performance status was evaluated using the American Society of Anesthesiologists (ASA) physical status classification. Poor performance was defined as $\geq$ class 3 ASA physical status, which indicates severe systemic disease with functional limitation [19]. The severity of airway stenosis was determined using the Myer-Cotton stenosis grading system: Grade I, $\leq 50 \%$ luminal stenosis; Grade II, 51-70\% luminal stenosis; Grade III, 71-99\% luminal stenosis; and Grade IV, no lumen [20]. Respiratory distress was defined as worsening oxygenation or dyspnea after the procedure requiring additional oxygen supplies for at least $24 \mathrm{~h}$. Excessive bleeding was defined as procedure-related bleeding which required transfusion or escalation in level of care.

Because all patients were in terminal stage with pulmonary metastasis from extra-pulmonary malignancy, the status of malignancy at the first bronchoscopic intervention was divided as follows. First, detection time of MCAO was divided as initial diagnosis of malignancy that had not yet been treated and disease progression of malignancy despite anti-cancer treatment. Second, we investigated the history of anti-cancer treatment after the first bronchoscopic intervention, and patients were divided into whether they received adjuvant treatment or not.

\section{Statistical analysis}

Data are presented as number (\%) for categorical variables and median (interquartile range [IQR]) for continuous variables. The Kaplan-Meier method was used to estimate overall survival after the first bronchoscopic intervention. A multivariable Cox proportional hazard regression analysis was used to identify independent prognostic factors associated with overall survival. Because the total number of patients was not large enough to allow all variables to be analyzed, demographic data and variables that seemed to be directly related to the procedure and survival were selectively included in the analysis. The appropriateness of the proportional hazards assumption was evaluated using plots of the log minus log of Kaplan-Meier survival against 
the log of time. Statistical differences were considered significant at $P<0.05$. All statistical analyses were performed using SPSS software (IBM SPSS Statistics ver. 22, Chicago, IL, USA).

\section{Results}

\section{Baseline characteristics}

Baseline characteristics of the study population are summarized in Table 1. Of the 98 patients, 60 (61.2\%) were males. The median age was 63 (IQR, 54-72) years old and the median body mass index (BMI) was $21.1 \mathrm{~kg} / \mathrm{m}^{2}$ (IQR, 18.1-24.3 kg/m²). Thirty-five patients (35.7\%) had an ASA physical status $\geq$ class 3 , and intubation before intervention was needed in $12(12.2 \%)$ patients due to respiratory failure. The most common primary site of malignancy was esophageal cancer (37.9\%), followed by thyroid cancer (16.3\%), head \& neck cancer (10.2\%), renal cell carcinoma (7.1\%), colorectal cancer (7.1\%), and lymphoma (5.1\%).

Characteristics of the MCAO site are summarized in Table 2. The most common site of MCAO was the trachea $(63.3 \%)$, followed by the left main bronchus $(21.4 \%)$

Table 1 Baseline characteristics

\begin{tabular}{ll}
\hline Variables & $N=98$ \\
\hline Age, years & $63(54-72)$ \\
Sex, male & $60(61.2)$ \\
Body mass index, $\mathrm{kg} / \mathrm{m}^{2}$ & $21.1(18.1-24.3)$ \\
Comorbidity & \\
Diabetes mellitus & $10(10.2)$ \\
Chronic liver disease & $8(8.2)$ \\
Cerebrovascular disease & $7(7.1)$ \\
Congestive heart disease & $6(6.1)$ \\
Chronic pulmonary disease & $3(3.1)$ \\
Poor performance status & \\
Intubation due to respiratory failure before intervention & $35(35.7)$ \\
Primary site of malignancy & $12(12.2)$ \\
Local extension & \\
Esophageal cancer & $63(64.4)$ \\
Thyroid cancer & $37(37.9)$ \\
Head \& neck cancer & $16(16.3)$ \\
Metastatic disease & $10(10.2)$ \\
Renal cell carcinoma & $35(35.6)$ \\
Colorectal cancer & $7(7.1)$ \\
Lymphoma & $7(7.1)$ \\
Others & $5(5.1)$ \\
\hline
\end{tabular}

Data are presented as $\mathrm{n}(\%)$ or the median (interquartile range)

${ }^{a}$ American Society of Anesthesiologists (ASA) physical status class $\geq 3$ means severe systemic disease with functional limitation

bSarcoma $(n=4)$, breast cancer $(n=3)$, hepatocellular carcinoma $(n=3)$, gastric cancer $(n=1)$, ovarian cancer $(n=1)$, neuroblastoma $(n=1)$, thymic cancer $(n=1)$, mesothelioma $(n=1)$, and peripheral nerve sheath tumor $(n=1)$
Table 2 Bronchoscopic findings

\begin{tabular}{ll}
\hline Variables & $N=98$ \\
\hline Site of lesion & \\
Single lesion & $93(94.9)$ \\
$\quad$ Trachea & $62(63.3)$ \\
$\quad$ Left main bronchus & $21(21.4)$ \\
$\quad$ Right main bronchus & $6(6.1)$ \\
$\quad$ Right bronchus intermedius & $1(1.0)$ \\
$\quad$ Lobar bronchus & $3(3.1)$ \\
Extended lesion & $5(5.1)$ \\
$\quad$ Trachea and each or both bronchi & $3(3.1)$ \\
$\quad$ Both main bronchi & $2(2.0)$ \\
Type of obstruction & \\
Endobronchial lesion & $29(29.6)$ \\
Extrinsic compression & $15(15.3)$ \\
Mixed lesion & $54(55.1)$ \\
Severity of stenosis (Myer and Cotton Grade) & \\
II & $25(25.5)$ \\
III & $55(56.1)$ \\
IV & $18(18.4)$ \\
Fistula between trachea and esophagus & $30(22-38)$ \\
\hline Dat are presented as $n$ & $8(8.2)$ \\
\hline
\end{tabular}

Data are presented as $\mathrm{n}(\%)$ or the median (interquartile range) MCAO malignant central airway obstruction

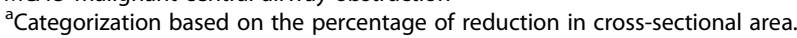
Grade 1, $\leq 50 \%$ lumenal stenosis; Grade II, 51-70\% lumenal stenosis; Grade III, $71-99 \%$ lumenal stenosis; Grade IV, no lumen

bength of MCAO was defined as the sum of the length of the obstructive lesions more than Grade II

and the right main bronchus (6.1\%). Mixed, endobronchial, and extrinsic obstructions were seen in 54 (55.1\%), 29 (29.6\%), and 15 (15.3\%) patients, respectively. Most patients $(74.5 \%)$ had $\geq 71 \%$ obstruction of cross sectional area (Grade III or IV). The median length of stenosis was $30 \mathrm{~mm}$ (IQR, 22-38 mm). Some patients $(8.2 \%)$ had a fistula between the trachea and the esophagus.

\section{Treatment modalities and complications}

The median time from diagnosis of MCAO to bronchoscopic intervention was 0.4 months (IQR, 0.2-1.0 months) (Table 3). Bronchoscopic interventions were usually performed using a combination of treatment modalities, including mechanical debulking (84.7\%), stent insertion (70.4\%), and laser cauterization (37.8\%). Thirty-five (35.7\%) patients underwent bronchoscopic intervention more than twice during their clinical courses. Finally, only 10 patients $(10.2 \%)$ had a technical failure. Of 22 patients who were diagnosed with MCAO as the initial diagnosis of malignancy, 7 (31.8\%) patients did not receive adjuvant treatment after interventional bronchoscopy. Of 76 patients who were diagnosed with MCAO due to 
Table 3 Treatment modalities and complications

\begin{tabular}{|c|c|}
\hline Variables & $N=98$ \\
\hline $\begin{array}{l}\text { Time interval from diagnosis of MCAO } \\
\text { to intervention, months }\end{array}$ & $0.4(0.2-1.0)$ \\
\hline \multicolumn{2}{|l|}{ Treatment modalities } \\
\hline Mechanical debulking & $83(84.7)$ \\
\hline Silicone stent & $69(70.4)$ \\
\hline Tube stent & $65(66.3)$ \\
\hline Y stent & $7(7.1)$ \\
\hline Laser & $37(37.8)$ \\
\hline Tracheostomy & $4(4.1)$ \\
\hline \multicolumn{2}{|l|}{ Number of interventional bronchoscopies } \\
\hline 1 & $63(64.3)$ \\
\hline$\geq 2$ & $35(35.7)$ \\
\hline Technical failure & $10(10.2)$ \\
\hline MCAO as initial diagnosis of malignancy & $22(22.4)$ \\
\hline $\begin{array}{l}\text { No adjuvant treatment after } \\
\text { interventional bronchoscopy }\end{array}$ & $7(7.1)$ \\
\hline Adjuvant radiation therapy & $10(10.2)$ \\
\hline Adjuvant chemotherapy & $6(6.1)$ \\
\hline Adjuvant surgical resection & $2(2.0)$ \\
\hline MCAO as disease progression of malignancy & $76(77.6)$ \\
\hline $\begin{array}{l}\text { No adjuvant treatment after } \\
\text { interventional bronchoscopy }\end{array}$ & $35(35.7)$ \\
\hline Adjuvant radiation therapy & $28(28.6)$ \\
\hline Adjuvant chemotherapy & $18(18.4)$ \\
\hline Adjuvant surgical resection & $1(1.0)$ \\
\hline Acute complications & $20(20.4)$ \\
\hline Respiratory distress & $13(13.3)$ \\
\hline Excessive bleeding & $10(10.2)$ \\
\hline Pneumothorax & $3(3.1)$ \\
\hline Procedure-related death ${ }^{a}$ & $3(3.1)$ \\
\hline 30-day mortality & $13(13.3)$ \\
\hline Chronic complications & $25(25.5)$ \\
\hline Mucostasis & 19 (19.4) \\
\hline Granulation tissue overgrowth & $10(10.2)$ \\
\hline Stent migration & $6(6.1)$ \\
\hline
\end{tabular}

Data are presented as $\mathrm{n}$ (\%) or the median (interquartile range) MCAO malignant central airway obstruction

Patients could undergo more than one adjuvant treatment

Patients could have more than one complication

Three patients died from tension pneumothorax, excessive bleeding, and pneumonia, respectively

progression of their malignancy, 35 (46.1\%) did not receive adjuvant treatment after interventional bronchoscopy.

Acute complications included respiratory distress $(n=13)$, excessive bleeding $(n=10)$, and pneumothorax $(n=3)$ (Table 3). Procedure-related deaths occurred in three patients from tension pneumothorax, excessive bleeding, and pneumonia, respectively. Although chronic complications including mucostasis $(n=19)$, granulation tissue overgrowth $(n=10)$, and stent migration $(n=6)$ occurred not infrequently, most complications were manageable with additional procedures.

\section{Survival and prognosis}

Figure 1 shows the overall survival after bronchoscopic intervention according to primary site of malignancy, type of obstruction, and adjuvant treatment or not after interventional bronchoscopy. Median survival was 7 months and 30-day mortality was $13.3 \%$. Survival rates at 1 year, 2 years, and 5 years were $34.7 \%, 22.4 \%$, and $11.2 \%$, respectively.

Table 4 shows independent prognostic factors related to mortality based on analysis with univariate and multivariate Cox proportional hazard regression. Because the plots of the log minus log of Kaplan-Meier survival against the log of time for all the variables seemed to be parallel, the hazards can be considered proportional. According to these analyses, overall survival was independently associated with primary site of malignancy, type of obstruction, and adjuvant treatment. Patients with thyroid cancer or lymphoma had better survival than those with other primary malignancies (adjusted hazard ratio [aHR], 0.245; 95\% confidence interval [CI], $0.104-0.573 ; P=0.001)$. Mixed lesions were significantly associated with worse survival compared to endobronchial lesions (aHR, 1.951; 95\% CI, 1.084-3.510; $P=0.026$ ). Patients with MCAO receiving adjuvant treatment had better survival than those with MCAO not receiving adjuvant treatment (aHR, 0.519; 95\% CI, 0.301-0.895; $P=0.018$ ).

\section{Discussion}

In patients with $\mathrm{MCAO}$, bronchoscopic intervention can provide significant palliation $[1,21,22]$. In particular, bronchoscopic intervention may relieve life-threatening obstruction and provide better opportunities for other therapeutic modalities such as radiation and chemotherapy in patients with respiratory failure caused by MCAO [23]. This study revealed that bronchoscopic interventions such as mechanical debulking, laser, and stent insertion could be performed safely and successfully in most patients with MCAO due to extra-pulmonary malignancy. In addition, we found that poor survival was associated with primary malignancy site, mixed lesions, and not receiving adjuvant treatment after interventional bronchoscopy.

Recently, cancer survival has consistently increased because of advances in early detection and treatment and aging of the population [24]. In this respect, MCAO is importantly associated with a major reduction in quality of life and survival [3]. As the effectiveness of bronchoscopic intervention in patients with MCAO is well- 


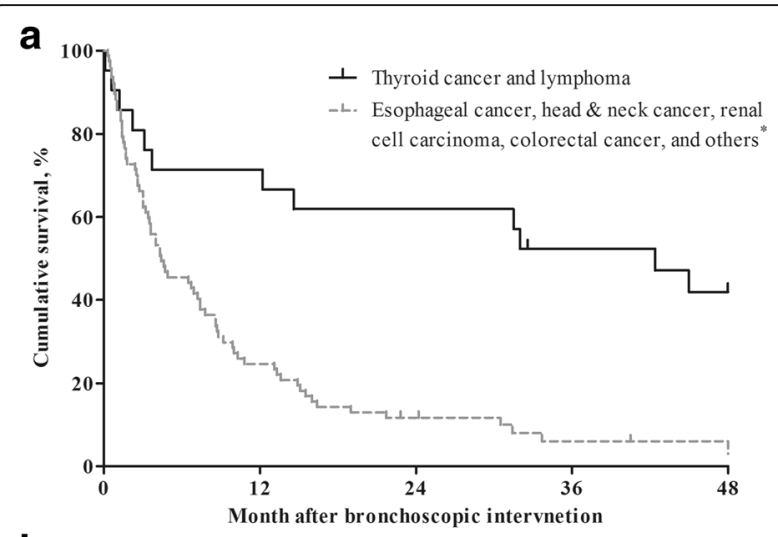

b

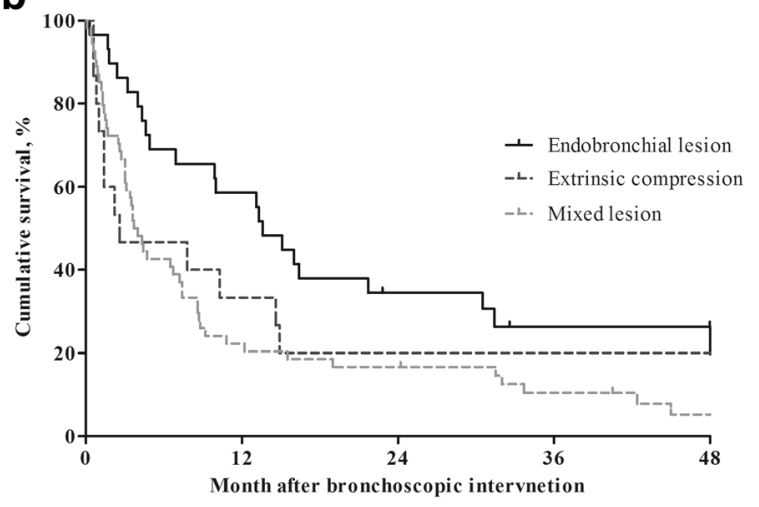

C

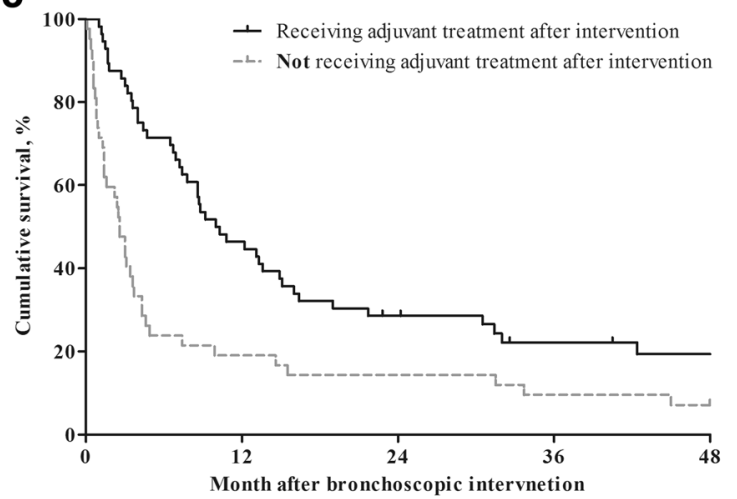

Fig. 1 Overall survival of patients after interventional bronchoscopy. Survival based on (a) primary site of malignancy, (b) type of obstruction, and (c) receiving adjuvant treatments or not after interventional bronchoscopy. MCAO, malignant central airway obstruction. * Sarcoma $(n=4)$, breast cancer $(n=3)$, hepatocellular carcinoma $(n=3)$, gastric cancer $(n=1)$, ovarian cancer $(n=1)$, neuroblastoma $(n=1)$, thymic cancer $(n=1)$, mesothelioma $(n=1)$, and peripheral nerve sheath tumor $(n=1)$

known $[1,6,11-14,25,26]$, bronchoscopic intervention is a preferred palliative therapy for relief of MCAO [21, 22]. However, most research is limited to patients with MCAO due to primary pulmonary malignancy $[25,26]$, or to a small proportion of patients with MCAO due to extra-pulmonary malignancy $[1,6,11-15]$. Furthermore, previous studies performed analysis without separating patients based on the primary site of malignancy. Although some reports targeted patients with MCAO due to extra-pulmonary malignancy, only a small number of patients were included [27-29]. For these reasons, previous reports were limited when analyzing treatment outcomes and prognostic factors in patients with $\mathrm{MCAO}$ due to extra-pulmonary malignancy.

In the present study, the technical success rate was $90.8 \%$, and acute complication- and procedure-related mortality were $20.4 \%$ and $3.1 \%$, respectively. Because there are few reports regarding bronchoscopic intervention in patients with MCAO due to extra-pulmonary malignancy, it is difficult to compare clinical outcomes with previous reports. Nonetheless, the technical success rate of the present study was as high as previous reports of interventional bronchoscopy in patients with MCAO due to mainly primary pulmonary malignancy, which was $88-100 \%[1,6,14,25,26]$. However, acute complications and procedure-related mortality were slightly higher in the present study than in previous studies, which were $3-10 \%[6,11,25,30]$ and $1 \%[6,12,14,30]$, respectively. Considering that most of our patients had terminal-stage cancer and almost half of the patients had no further options for anti-cancer treatment in this study, we think that these technical success rates and complication rates are reasonable.

In this study, we also investigated prognostic factors associated with overall survival after the first bronchoscopic intervention. First, survival depends on the primary site of malignancy. We expected that patients with MCAO due to thyroid cancer (which is known to be slowly progressive) and lymphoma (known to have good response to chemoradiation therapy) would have better survival than those with MCAO due to other malignancies. Second, mixed lesions were a poor prognostic factor compared to endobronchial lesions. Mixed lesions frequently require a multimodal approach and can be associated with increased complications and mortality $[15,30]$. Third, patients with MCAO not receiving adjuvant treatment after interventional bronchoscopy had a poor prognosis. As seen in previous studies, survival was poor among patients who had exhausted all options such as radiation, chemotherapy, and surgery before bronchoscopic intervention $[6,15,25]$. On the other hand, BMI, poor performance status, as evaluated by ASA score, intubation state before intervention, and detection time of MCAO were not significantly associated with increased mortality in our study. We hypothesize that this was because their poor general condition was rapidly resolved and did not influence long term survival after successful intervention. Thus, bronchoscopic intervention should not be limited to these populations.

This report has several limitations. First, selection bias may have influenced the significance of our results due 
Table 4 Prognostic factors related to mortality

\begin{tabular}{|c|c|c|c|c|c|}
\hline \multirow[t]{2}{*}{ Variables } & \multirow[t]{2}{*}{ N } & \multicolumn{2}{|c|}{ Univariable Cox regression } & \multicolumn{2}{|c|}{ Multivariable Cox regression } \\
\hline & & $\begin{array}{l}\text { Unadjusted HR } \\
(95 \% \mathrm{Cl})\end{array}$ & $P$ & $\begin{array}{l}\text { Adjusted HR } \\
(95 \% \mathrm{Cl})\end{array}$ & $P$ \\
\hline Age, years & - & $0.996(0.982-1.010)$ & 0.596 & $1.005(0.981-1.029)$ & 0.679 \\
\hline Sex, male & 60 & $1.224(0.792-1.890)$ & 0.363 & $0.721(0.398-1.307)$ & 0.282 \\
\hline Body mass index, $\mathrm{kg} / \mathrm{m}^{2}$ & - & $0.925(0.869-0.984)$ & 0.013 & $0.968(0.901-1.041)$ & 0.381 \\
\hline Poor performance status ${ }^{a}$ & 35 & $1.201(0.776-1.859)$ & 0.411 & $0.801(0.470-1.363)$ & 0.413 \\
\hline Intubation due to respiratory failure before intervention & 12 & $1.308(0.692-2.470)$ & 0.409 & $1.110(0.517-2.384)$ & 0.788 \\
\hline \multicolumn{6}{|l|}{ Primary site of malignancy } \\
\hline Esophageal, head \& neck, renal, and colorectal cancer and others ${ }^{\mathrm{b}}$ & 77 & Reference & & Reference & \\
\hline Thyroid cancer and lymphoma & 21 & $0.316(0.174-0.575)$ & $<0.001$ & $0.245(0.104-0.573)$ & 0.001 \\
\hline \multicolumn{6}{|l|}{ Site of lesion } \\
\hline Single lesion & 93 & Reference & & Reference & \\
\hline Extended lesion & 5 & $3.399(1.333-8.663)$ & 0.010 & $1.407(0.433-4.571)$ & 0.571 \\
\hline \multicolumn{6}{|l|}{ Type of obstruction } \\
\hline Endobronchial lesion & 29 & Reference & & Reference & \\
\hline Extrinsic compression & 15 & $1.261(0.624-2.551)$ & 0.518 & $0.879(0.321-2.404)$ & 0.802 \\
\hline Mixed lesion & 54 & $1.914(1.171-3.130)$ & 0.010 & $1.951(1.084-3.510)$ & 0.026 \\
\hline \multicolumn{6}{|l|}{ Severity of stenosis (Myer and Cotton Grade) ${ }^{c}$} \\
\hline$\|$ and II & 80 & Reference & & Reference & \\
\hline IV & 18 & $1.057(0.617-1.809)$ & 0.841 & $0.556(0.276-1.120)$ & 0.100 \\
\hline Length of $\mathrm{MCAO}^{\mathrm{d}}, \mathrm{mm}$ & - & $1.007(0.989-1.024)$ & 0.468 & $1.016(0.988-1.044)$ & 0.274 \\
\hline \multicolumn{6}{|l|}{ Number of interventional bronchoscopies } \\
\hline 1 & 63 & Reference & & Reference & \\
\hline$\geq 2$ & 35 & $0.721(0.461-1.129)$ & 0.153 & $0.787(0.461-1.342)$ & 0.378 \\
\hline \multicolumn{6}{|l|}{ Detection time of MCAO } \\
\hline Initial diagnosis of malignancy that have not yet been treated & 22 & Reference & & Reference & \\
\hline Disease progression of malignancy despite anti-cancer treatment & 76 & $1.963(1.146-3.362)$ & 0.014 & $1.541(0.710-3.347)$ & 0.274 \\
\hline \multicolumn{6}{|l|}{ Adjuvant treatment after interventional bronchoscopy } \\
\hline Not receiving adjuvant treatment & 56 & Reference & & Reference & \\
\hline Receiving adjuvant treatment & 42 & $0.501(0.327-0.768)$ & 0.002 & $0.519(0.301-0.895)$ & 0.018 \\
\hline
\end{tabular}

HR hazard ratio, $\mathrm{Cl}$ confidential interval, MCAO malignant central airway obstruction

${ }^{a}$ American Society of Anesthesiologists (ASA) physical status class $\geq 3$ means severe systemic disease with functional limitation

${ }^{\mathrm{b}}$ Sarcoma $(n=4)$, breast cancer $(n=3)$, hepatocellular carcinoma $(n=3)$, gastric cancer $(n=1)$, ovarian cancer $(n=1)$, neuroblastoma $(n=1)$, thymic cancer $(n=1)$, mesothelioma $(n=1)$, and peripheral nerve sheath tumor $(n=1)$

'Categorization based on the percentage of reduction in cross-sectional area. Grade 1, $\leq 50 \%$ lumenal stenosis; Grade II, 51-70\% lumenal stenosis; Grade III, 71-99\% lumenal stenosis; Grade IV, no lumen

dength of MCAO was defined as the sum of the length of the obstructive lesions more than Grade II

to the retrospective design at a single center. Second, there have been advancements in treatment options for patients with terminal malignancy, such as chemoradiotherapy and supportive care throughout the study period. These advancements might have influenced recent patients, leading to slower disease progression and better survival than former patients. Third, there may be a lead-time bias in our results. Because all the patients were in terminal stage with pulmonary metastasis from extra-pulmonary malignancy at the time of diagnosis for MCAO, we divided all patients by detection time and receiving adjuvant treatment or not. Although we adjusted for these variables in the multivariable Cox proportional hazard regression analysis, lead-time bias may have influenced our results. Fourth, the number of patients was relatively small for multivariate analysis, including many prognostic variables. Therefore, interpretation of the main results will require caution. Finally, we could not evaluate spirometric data, quality of life, and symptom scores before and after treatment. This would be vital since the interventional procedures for MCAO are primarily palliative. 


\section{Conclusions}

In conclusion, bronchoscopic intervention could be a safe and effective procedure for terminal stage cancer patients with extra-pulmonary malignancies with lung metastasis. Poor prognosis may be related with MCAO due to cancer other than thyroid cancer or lymphoma, mixed lesions, and no adjuvant treatment after bronchoscopic intervention. We hope that this study can help clinicians select candidates that will benefit from bronchoscopic intervention.

\section{Funding}

None.

\section{Availability of data and materials}

The datasets used and/or analyzed during the current study are available from the corresponding author on reasonable request.

\section{Authors' contributions}

BS has been involved in collection and assembly of data, data analysis and interpretation, and manuscript writing. BC has been involved in collection and assembly of data, data analysis and interpretation, and review. HK has been involved in conception and design and review. BHJ has been involved in conception and design, collection and assembly of data, data analysis and interpretation, manuscript writing, and review. All authors read and approved the final manuscript.

\section{Ethics approval and consent to participate}

This study obtained approval from the institutional review board (IRB no. 2017-01033) to review and publish information obtained from patient records. The need for informed consent was waived because patient information was anonymized and de-identified prior to analysis.

\section{Consent for publication}

Not applicable.

\section{Competing interests}

The authors declare that they have no competing interests.

\section{Publisher's Note}

Springer Nature remains neutral with regard to jurisdictional claims in published maps and institutional affiliations.

\section{Author details}

'Department of Internal Medicine, Yonsei University Wonju College of Medicine, Wonju, South Korea. ${ }^{2}$ Department of Pulmonary and Critical Care Medicine, Kyung Hee University Hospital at Gangdong, School of Medicine, Kyung Hee University, Seoul, South Korea. ${ }^{3}$ Division of Pulmonary and Critical Care Medicine, Department of Internal Medicine, Samsung Medical Center, Sungkyunkwan University School of Medicine, 81 Irwon-ro, Gangnam-gu, Seoul 06351, South Korea.

Received: 27 November 2017 Accepted: 6 March 2018

Published online: 13 March 2018

\section{References}

1. Ost DE, Ernst A, Grosu HB, Lei X, Diaz-Mendoza J, Slade M, Gildea TR, Machuzak MS, Jimenez CA, Toth J, et al. Therapeutic bronchoscopy for malignant central airway obstruction: success rates and impact on dyspnea and quality of life. Chest. 2015;147(5):1282-98.

2. Macha $\mathrm{HN}$, Becker $\mathrm{KO}$, Kemmer HP. Pattern of failure and survival in endobronchial laser resection. A matched pair study. Chest. 1994;105(6):1668-72.

3. Walser EM, Robinson B, Raza SA, Ozkan OS, Ustuner E, Zwischenberger J. Clinical outcomes with airway stents for proximal versus distal malignant tracheobronchial obstructions. J Vasc Interv Radiol. 2004;15(5):471-7.

4. Wood DE. Management of malignant tracheobronchial obstruction. Surg Clin North Am. 2002;82(3):621-42.
5. Nihei K, Ishikura S, Kawashima M, Ogino T, Ito Y, Ikeda H. Short-course palliative radiotherapy for airway stenosis in non-small cell lung cancer. Int J Clin Oncol. 2002;7(5):284-8

6. Jeon K, Kim H, Yu CM, Koh WJ, Suh GY, Chung MP, Kwon OJ. Rigid bronchoscopic intervention in patients with respiratory failure caused by malignant central airway obstruction. J Thorac Oncol. 2006;1(4):319-23.

7. Seijo LM, Sterman DH. Interventional pulmonology. N Engl J Med. 2001; 344(10):740-9.

8. Greelish JP, Friedberg JS. Secondary pulmonary malignancy. Surg Clin North Am. 2000;80(2):633-57.

9. Marchioni A, Lasagni A, Busca A, Cavazza A, Agostini L, Migaldi M, Corradini P, Rossi G. Endobronchial metastasis: an epidemiologic and clinicopathologic study of 174 consecutive cases. Lung Cancer (Amsterdam, Netherlands). 2014;84(3):222-8.

10. Kreisman H, Wolkove N, Finkelstein HS, Cohen C, Margolese R, Frank H. Breast cancer and thoracic metastases: review of 119 patients. Thorax. 1983:38(3):175-9.

11. Dalar L, Ozdemir C, Abul Y, Karasulu L, Sokucu SN, Akbas A, Altn S. Therapeutic bronchoscopic interventions for malignant airway obstruction: a retrospective study from experience on 547 patients. Medicine. 2016; 95(23):e3886.

12. Chen CH, Wu BR, Cheng WC, Chen CY, Chen WC, Hsia TC, Liao WC, Tu $\mathrm{CY}$, Hsu WH. Interventional pulmonology for patients with central airway obstruction: an 8-year institutional experience. Medicine. 2017;96(2):e5612

13. Amjadi K, Voduc N, Cruysberghs Y, Lemmens R, Fergusson DA, Doucette S, Noppen M. Impact of interventional bronchoscopy on quality of life in malignant airway obstruction. Respiration. 2008;76(4):421-8.

14. Razi SS, Lebovics RS, Schwartz G, Sancheti M, Belsley S, Connery CP, Bhora FY. Timely airway stenting improves survival in patients with malignant central airway obstruction. Ann Thorac Surg. 2010;90(4):1088-93.

15. Grosu HB, Eapen GA, Morice RC, Jimenez CA, Casal RF, Almeida FA, Sarkiss $M G$, Ost DE. Stents are associated with increased risk of respiratory infections in patients undergoing airway interventions for malignant airways disease. Chest. 2013;144(2):441-9.

16. Colt HG, Dumon JF. Airway stents. Present and future. Clin Chest Med. 1995; 16(3):465-78.

17. Kim H. Stenting therapy for stenosing airway disease. Respirology (Carlton, Vic). 1998;3(4):221-8

18. Shin B, Kim K, Jeong BH, Eom JS, Song WJ, Kang HK, Kim H. Clinical significance of differentiating post-intubation and post-tracheostomy tracheal stenosis. Respirology (Carlton, Vic). 2017;22(3):513-20.

19. Owens WD, Felts JA, Spitznagel EL Jr. ASA physical status classifications: a study of consistency of ratings. Anesthesiology. 1978;49(4):239-43.

20. Myer CM 3rd, O'Connor DM, Cotton RT. Proposed grading system for subglottic stenosis based on endotracheal tube sizes. Ann Otol Rhinol Laryngol. 1994;103(4 Pt 1):319-23.

21. Mitchell PD, Kennedy MP. Bronchoscopic management of malignant airway obstruction. Adv Ther. 2014:31(5):512-38.

22. Guibert N, Mhanna L, Droneau S, Plat G, Didier A, Mazieres J, Hermant C. Techniques of endoscopic airway tumor treatment. J Thorac Dis. 2016;8(11): 3343-60.

23. Venuta F, Rendina EA, De Giacomo T, Mercadante E, Ciccone AM, Aratari MT, Moretti M, Coloni GF. Endoscopic treatment of lung cancer invading the airway before induction chemotherapy and surgical resection. Eur J Cardiothorac Surg. 2001;20(3):464-7.

24. Miller KD, Siegel RL, Lin CC, Mariotto AB, Kramer JL, Rowland JH, Stein KD, Alteri R, Jemal A. Cancer treatment and survivorship statistics, 2016. CA Cancer J Clin. 2016;66(4):271-89.

25. Guibert N, Mazieres J, Lepage B, Plat G, Didier A, Hermant C. Prognostic factors associated with interventional bronchoscopy in lung cancer. Ann Thorac Surg. 2014;97(1):253-9.

26. Stratakos G, Gerovasili V, Dimitropoulos C, Giozos I, Filippidis FT, Gennimata S, Zarogoulidis P, Zissimopoulos A, Pataka A, Koufos N, et al. Survival and quality of life benefit after endoscopic management of malignant central airway obstruction. J Cancer. 2016;7(7):794-802.

27. Fournel C, Bertoletti L, Nguyen B, Vergnon JM. Endobronchial metastases from colorectal cancers: natural history and role of interventional bronchoscopy. Respiration. 2009;77(1):63-9.

28. Chaussende A, Hermant C, Tazi-Mezalek R, Favrolt N, Hureaux J, Fournier C, Lorut C, Paganin F, Ngo MT, Vandemoortele T, et al. Endobronchial 
metastases from melanoma: a survival analysis. Clin Respir J. 2017;11(6): 1006-1011. (Epub 2016 Feb 25).

29. Dalar L, Ozdemir C, Sokucu SN, Karasulu L, Altin S. Bronchoscopic palliation to treat endobronchial metastasis of the tracheobronchial tree. Respir Investig. 2016;54(2):116-20.

30. Ost DE, Ernst A, Grosu HB, Lei X, Diaz-Mendoza J, Slade M, Gildea TR, Machuzak M, Jimenez CA, Toth J, et al. Complications following therapeutic bronchoscopy for malignant central airway obstruction: results of the AQuIRE registry. Chest. 2015;148(2):450-71.

Submit your next manuscript to BioMed Central and we will help you at every step:

- We accept pre-submission inquiries

- Our selector tool helps you to find the most relevant journal

- We provide round the clock customer support

- Convenient online submission

- Thorough peer review

- Inclusion in PubMed and all major indexing services

- Maximum visibility for your research

Submit your manuscript at www.biomedcentral.com/submit 